\title{
BIOSYNTHESIS OF ALKYL-ETHER CONTAINING LIPID FROM DIHYDROXYACETONE PHOSPHATE
}

$$
\text { Amiya K. Hajra }
$$

Mental Ilealth Research Institute and Department of Biological Chemistry, University of Michigan, Ann Arbor, Michigan 48104.

Received August 29, 1969

Summary: A lipid, stable to alkaline methanolysis, is formed when liver mitochondria or brain microsomes are incubated with dihydroxyacetone phosphate, long chain alcohol, ATP, $\mathrm{CoA}, \mathrm{NaF}$ and $\mathrm{Mg}+$. The lipid has been identified as alky1 dihydroxyacetone phosphate. This 1ipid is reduced by NADPH to 1-alky1 g1ycero13-phosphate and is further acylated to form 1-alky1 2-acyl glycerol-3-phosphate.

The ether-containing lipids are very widespread in nature (1). Recently Snyder and coworkers $(2,3)$ presented evidence that these 1ipids are formed in tumor cells from long chain alcoho1 and D-glyceraldehyde-3-phosphate (GADP) ${ }^{1}$. During the course of investigation of DHAP-containing lipid, it was found that an alkyl-ether-containing lipid is biosynthesized in normal guinea pig liver mitochondria or in mouse brain microsomes from long chain alcohol and DHAP in the presence of necessary cofactors. Evidence presented here indicates that GADP is not an obligatory intermediate in this system.

Materials and Methods: $1-{ }^{14} \mathrm{C}$-Hexadecanol was purchased from Amersham/Searle (Des Plaines). ${ }^{32}$ P-Labeled DHAP was prepared by enzymatic phosphorylation of dihydroxyacetone (4). Labeled fructose-6-phosphate was prepared by enzymatic (hexukinase) phosphorylation of rructose by $\gamma-32$ P-ATP and oxidized with periodic acid (5) to form ${ }^{32} \mathrm{p}-\mathrm{GADP}$. Crystalline enzymes were from Boehringer-Mannheim (New York). Hexadecanol was emulsified in Tris-HC1 buffer (0.1 M, pH 7.6) with Triton X-100 (Rohm and Haas, Philadelphia).

Incubation conditions are described in Table 1 . The reaction was stopped by adding $4.5 \mathrm{ml}$ chloroform-methanol (1-2) and the lipid was extracted as

${ }^{1}$ Abbreviations used: GADP - D-glyceraldehyde-3-phosphate; DHAP - dihydroxyacetone phosphate; GP - g1ycero1-3-phosphate. 
Table 1. Requirements for the incorporation of ${ }^{32} \mathrm{P}$-DHAP into alkali-stable 1ipid.

The incubation mixture contained Tris-HC1 buffer $(\mathrm{pH} 7.6,40 \mathrm{mM}), \mathrm{MgCl}_{2}$ $(4.2 \mathrm{mM}), \operatorname{ATP}(8.4 \mathrm{mM}), \operatorname{NaF}(8.4 \mathrm{mM})$, glutathione $(4.2 \mathrm{mM}), \operatorname{CoA}(.04 \mathrm{mM})$, hexadecanol $(0.5 \mathrm{mg})$, Triton X-100 $(0.5 \mathrm{mg}),{ }^{32} \mathrm{P}-\mathrm{DHAP}\left(0.6 \mathrm{mM}, 7 \times 10^{5} \mathrm{cpm}\right.$ in expt. A and $9 \times 10^{5} \mathrm{cpm}$ in expt. B) and either guinea pig liver mitochondria (expt. A, $1.6 \mathrm{mg}$ protein) or mouse brain (13-15 days old) microsomes (expt. B, $3.0 \mathrm{mg}$ protein) in a total volume of $1.2 \mathrm{~m}$. The mixture was incubated at $37^{\circ}$ for $1 \mathrm{hr}$. The radioactivity in the alkali-stable lipid was determined as described in the text.

\begin{tabular}{|c|c|c|}
\hline \multirow[t]{2}{*}{ System } & $\begin{array}{l}\text { xpt. A } \\
\text { ivity in alkali- } \\
\text { able lipid }\end{array}$ & $\begin{array}{c}\text { Expt. B } \\
\text { Radioactivity in alkali- } \\
\text { stable lipid }\end{array}$ \\
\hline & $\mathrm{cpm}$ & $\mathrm{cpm}$ \\
\hline Whole system & 5,300 & 1,950 \\
\hline - hexadecanol & 40 & 83 \\
\hline - ATP & 810 & 200 \\
\hline$-\mathrm{CoA}$ & 1,145 & 330 \\
\hline - glutathione & 5,320 & 1,865 \\
\hline$-\mathrm{MgCl}_{2}$ & 3,900 & 1,120 \\
\hline$-\mathrm{NaF}$ & 180 & 114 \\
\hline$+\mathrm{NADPH}(0.84 \mathrm{mM})$ & 200 & 230 \\
\hline$+\mathrm{NADPH}(0.84 \mathrm{mM})^{*}$ & 3,830 & 1,540 \\
\hline $\begin{array}{l}\text { - hexadecanol, } \\
\quad+\text { palmitate }(0.5 \mathrm{mg})\end{array}$ & 205 & - \\
\hline $\begin{array}{l}\text { - hexadecanol, } \\
\quad+\text { palmitaldehyde }(0.5 \mathrm{mg})\end{array}$ & 310 & - \\
\hline
\end{tabular}

* Added after 30 min incubation.

described previously (6). To the dry lipid $1.3 \mathrm{ml}$ of chloroform, $0.25 \mathrm{ml}$ methanol and $0.4 \mathrm{ml}$ of $0.5 \mathrm{~N} \mathrm{NaOH}$ in methanol were added. The alkaline methanolysis treatment was stopped after 10 min by adding $0.5 \mathrm{ml}$ of $6 \mathrm{~N} \mathrm{H}_{3} \mathrm{PO}_{4}$. After mixing and centrifuging, the upper layer was removed and the lower layer was washed with $1 \mathrm{~m} 1$ chloroform-methanol-water (3-48-47). The radioactivity in an a1iquot of the 1ower layer was determined. When formation of alkalistable 1ipid from $1-\mathrm{C}^{14}$-hexadecanol was determined, the unconverted radioactive substrate was removed by chromatography on a silicic acid column. Other method: and materials were described previously $(4,7,8)$. 
Cofactor requirements: The requirements for the formation of alkali-stable lipid are given in Table 1. It is seen that ATP, COA and NaF are necessary. $\mathrm{F}^{-}$probably inhibits the hydrolysis of phosphomonoester bonds. $\mathrm{Mg}^{++}$was found to increase the activity. Addition of EDTA completely inhibited the enzymatic activity and $\mathrm{Mg}^{++}$could partially restore the activity. The long chain alcohol could not be replaced by a long chain aldehyde or a long chain fatty acid (Table 1) or by hexadecyl phosphate. When ${ }^{32} \mathrm{P}-\mathrm{GP}$ was used instead of ${ }^{32} \mathrm{P}-$ DHAP, no alkali-stable lipid was formed. However, alkali-stable lipid was formed when ${ }^{32}$ P-GADP was used instead of DHAP (see below). NADPH was found to inhibit the formation of the lipid (Table 1); however, if NADPH was added some time after the start of the incubation, the properties of biosynthesized 1ipid were different (see below). NADH partly inhibited the reaction. The requirements for the incorporation of $1-C^{14}$-hexadecanol in the presence of DHAP into alkali-stable lipid were found to be similar as shown in Table 1. Characterization of the 1ipids: The ${ }^{32} \mathrm{P}-$ and ${ }^{14} \mathrm{C}$-labeled alkali-stable lipids were found to have chromatographic properties similar to acyl DHAP (Fig. 1). However, the former lipid is not hydrolyzed by alkali ( $1 \mathrm{~N}, 10 \mathrm{~min}$ at $37^{\circ}$ ) or by acid $\left(1 \mathrm{~N}, 10 \mathrm{~min}\right.$ at $\left.100^{\circ}\right)$. The lipid was also found to be stable towards acid in the presence of $\mathrm{HgCl}_{2}$ unlike alkenyl ethers. When reduced with $\mathrm{NaBH}_{4}$ (8), the chromatographic properties of the lipid became similar to lysophosphatidic acid (Fig. 1). The reduced lipid was also stable towards acid and alkali. When NADPH was added to the incubation mixture after $30 \mathrm{~min}$ of incubation the resulting phospholipid was found to migrate with phosphatidic acid (Fig. 1). After alkaline methanolysis this lipid had a migration rate similar to that of lysophosphatidic acid. When the lipid that was formed in the presence of $\mathrm{NADPH}$ (Fig. 1C) was treated with snake venom phospholipase A, the major resultant lipid had chromatographic properties similar to that of $1 y s o-$ phosphatidic acid.

The presence of ether linkage was confirmed by treatment of the alkalistable lipid formed from $1-\mathrm{C}^{14}$-hexadecanol and ${ }^{32} \mathrm{P}$-DHAP by $\operatorname{LiAlH}_{4}(9,10)$. The 


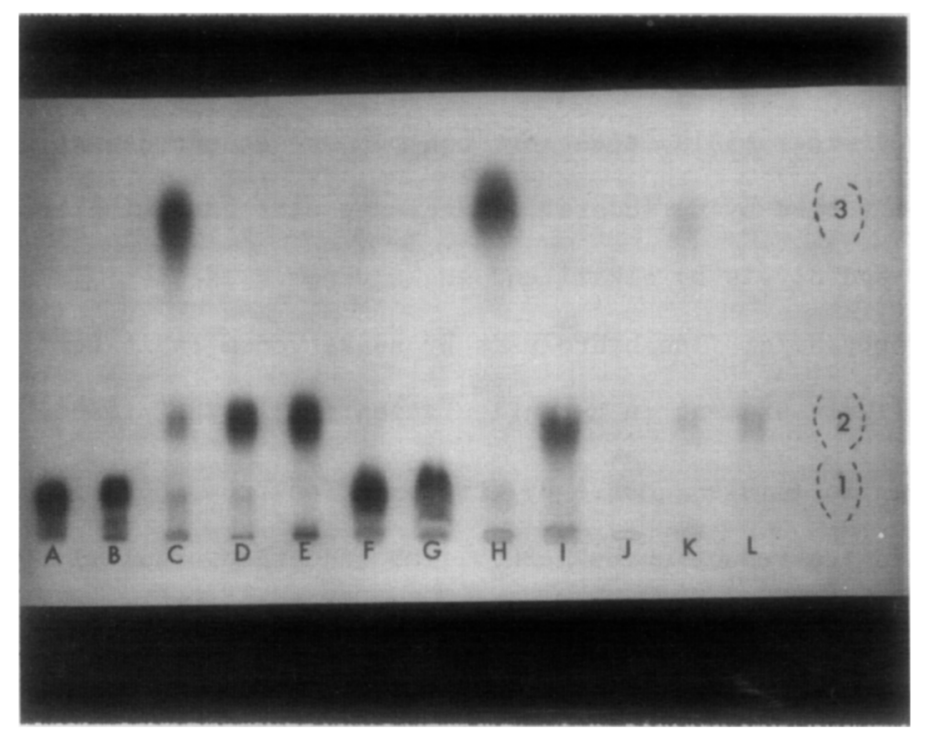

Fig. 1. Autoradiogram of ${ }^{32} \mathrm{P}$ - and ${ }^{14} \mathrm{C}$-labeled lipids after separation by thin layer chromatography (7) formed under various conditions. A. Radioactive lipid formed by incubation of hexadecanol and ${ }^{32} \mathrm{P}-\mathrm{DHAP}$ with various cofactors in liver mitochondria (see Table 1, expt. A). Both alkali-stable lipid and acyl DHAP formed with endogenous fatty acid are present. $\underline{B}$. The lipid in $A$ after alkaline methanolysis. $\underline{C}$. Radioactive lipid formed when NADPH is added after $30 \mathrm{~min}$ to the incubation mixture. The most rapidly moving spot is a mixture of a smal1 amount of diacyl GP and alkyl acyl GP. D. Lipid in C after alkaline methanolysis. E. The lipid as in B after $\mathrm{NaBH}_{4}$ reduction. $\underline{F}-\underline{I}$. Same as $A-D$ but brain microsomes were used instead of liver mitochondria. J. The radioactive lipid formed from $1-\mathrm{C}^{14}$-hexadecanol and DHAP in liver mitochondria after alkaline methanolysis. K. $\mathrm{C}^{14}-1$ ipid formed before alkaline methanolysis from 1-C 14 hexadecanol when $\mathrm{NADPH}$ is present. $\mathrm{L}$. Lipid in $\mathrm{K}$ after alkaline methanolysis. The positions of known lipids are also shown. (1) acy1 DHAP. (2) acyl GP. (3) dlacyl GP.

${ }^{32} \mathrm{P}$ became water soluble and the ${ }^{14} \mathrm{C}-1$ ipid took on the behavior of chimy 1 alcohol with which it comigrated in various chromatographic systems (10). When this product was treated with $\mathrm{NaIO}_{4}$ the product migrated with the $\mathrm{NaIO}_{4}$ oxidation product of chimyl alcohol.

The evidence presented above suggests the formation of alkyl ether containing lipid by the following scheme:

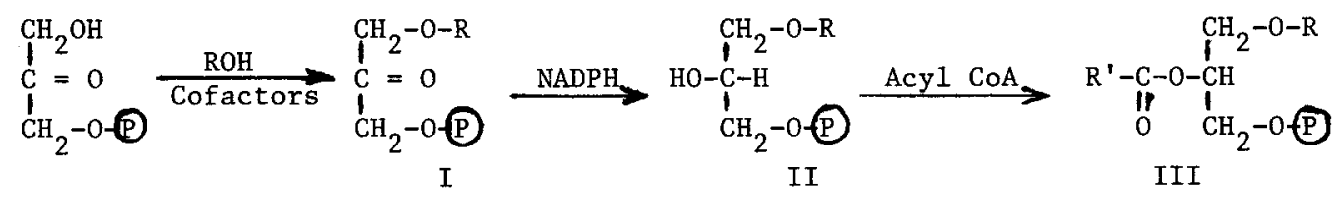

Scheme 1. 
The presence of an alkyl ether group and its position is inferred by resistance of the lipid to hydrolysis by acid or alkali, the nature of the product formed after $\mathrm{LiAlII}_{4}$ treatment and the subsequent oxidation of the neutral lipid formed by periodate. The presence of an acyl group in III is indicated by hydrolysis by alkali and snake venom. The acyl group comes from endogenous fatty acid. The hydrolysis by snake venom indicates further that glycero1 is 1ike1y present in L-configuration (11). The presence of a carbony1 group in I is suggested by its formation from DHAP, its chromatographic properties and its reduction by $\mathrm{NaBH}_{4}{ }^{\cdot}$ The reduction of alky1 DHAP by NADPH is probably similar to the reduction of acyl DHAP (12).

D-glyceraldehyde-3-phosphate vs. dihydroxyacetone phosphate: As mentioned above, ${ }^{32} \mathrm{P}$-GADP also acted as a substrate in the formation of the ethercontaining lipid. The requirements and the nature of the lipid formed were identical to that from DHAP. Either triose phosphate might be the true reactant, since they are rapidly interconverted by triose phosphate isomerase.

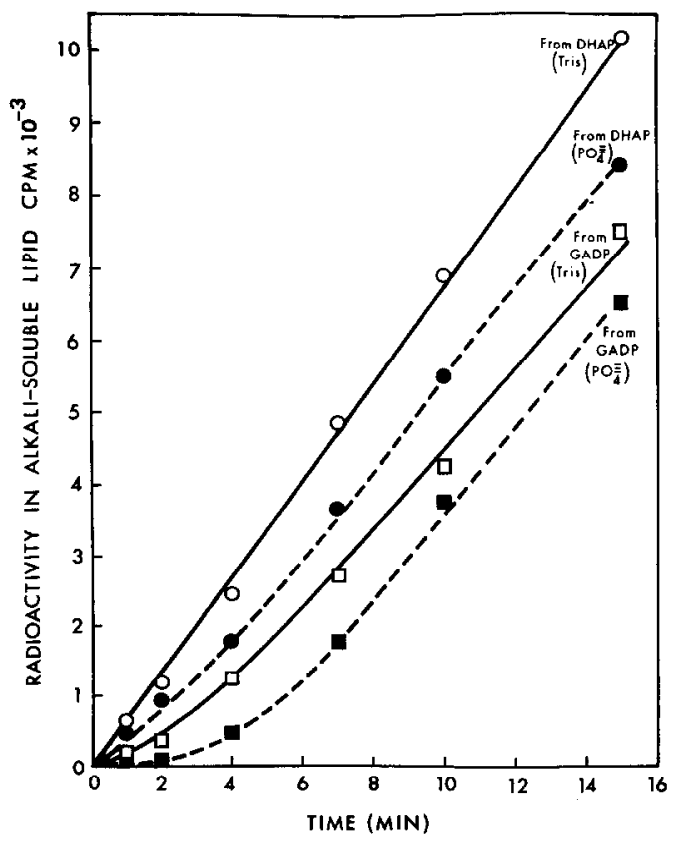

Fig. 2. Time course of formation of radioactive alkali-stable lipid from either 32 P-DHAP or 32P-GADP in Tris $(60 \mathrm{mM})$ or phosphate $(60 \mathrm{mM})$ buffers. The incubation condition is similar to that described in Table 1 . 
Considerable amount of isomerase activity was found in liver mitochondria or brain microsome which could not be completely removed by repeated washing (13). Several lines of evidence have been found which suggest that DHAP is not converted to GADP in the incubation mixture, and is the actual substrate for ether formation. When a time course of the formation of alkali-stable lipid from either DHAP or GADP was determined, a small but consistent lag of the formation of lipid from ${ }^{32}$ P-GADP was found (Fig. 2). The lag was more pronounced in phosphate buffer than in Tris buffer (Fig. 2) and it is known that phosphate partially inhibits triose phosphate isomerase (14). When GADP dehydrogenase was added to the incubation mixture, the incorporation of GADP was inhibited without much effect on DHAP incorporation (Table 2). On the other hand, addition of GP-dehydrogenase was found to inhibit the incorporation of both GADP and DHAP (Table 2). Hydrazine (1 mM) was found to inhibit GADP incorporation more than DHAP incorporation. Table 2. Effect of addition of different agents on the incorporation of
$32_{\text {P-DHAP and } 32 \text { P-GADP into alkali-stable lipid. }}$

The reaction mixture is similar to the one described in Table 1 , expt. A. Either ${ }^{32} \mathrm{P}$-DHAP $\left(0.6 \mu \mathrm{mole}, 1.2 \times 10^{6} \mathrm{cpm}\right)$ or ${ }^{32} \mathrm{P}-\mathrm{GADP}\left(0.6 \mu \mathrm{mole}, 1.1 \times 10^{6} \mathrm{cpm}\right)$ were used. Other additions were as stated below. The incubation was at $37^{\circ}$ for $15 \mathrm{~min}$.

\begin{tabular}{|c|c|c|}
\hline Addition & $\begin{array}{l}\text { Radioactive } \\
\text { substrate }\end{array}$ & $\begin{array}{c}\text { Radioactivity in alkali } \\
\text { stable lipid }\end{array}$ \\
\hline & & $\mathrm{cpm}$ \\
\hline 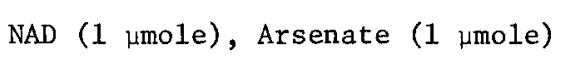 & 32 P-DHAP & 3,609 \\
\hline $\begin{array}{l}\text { NAD ( } 1 \text { mole }) \text {, Arsenate }(1 \mu \text { mole } \\
\quad+\text { GADP dehydrogenase }(40 \mu \mathrm{g})\end{array}$ & ${ }^{32} \mathrm{P}-\mathrm{DHAP}$ & 3,429 \\
\hline $\mathrm{NADH}(1 \mu$ mole $)$ & ${ }^{32} \mathrm{p}-\mathrm{DHAP}$ & 1,200 \\
\hline $\begin{array}{l}\text { NADH }(1 \mu \text { mole })+\text { GP dehydrogenase } \\
\quad(50 \mu \mathrm{g})\end{array}$ & 32 P-DHAP & 86 \\
\hline $\mathrm{NAD}(1 \mu \mathrm{mole})$, Arsenate $(1 \mu \mathrm{mole})$ & ${ }^{32} \mathrm{P}-\mathrm{GADP}$ & 3,115 \\
\hline $\begin{array}{l}\text { NAD }(1 \mu \text { mole }) \text {, Arsenate }(1 \mu \text { mole }) \\
\quad+\text { GADP dehydrogenase }(40 \mu g)\end{array}$ & $32 \mathrm{P}-\mathrm{GADP}$ & 300 \\
\hline $\mathrm{NADH}(1 \mu \mathrm{mole})$ & ${ }^{32} \mathrm{P}-\mathrm{GADP}$ & 988 \\
\hline $\begin{array}{l}\text { NADH }(1 \mu \text { mole })+\text { GP dehydrogenase } \\
(50 \mu g)\end{array}$ & ${ }^{32} \mathrm{P}-\mathrm{GADP}$ & 111 \\
\hline
\end{tabular}


These results support the proposed pathway for the biosynthesis of a1ky1ether containing lipid shown in scheme 1 . The alky1 acyl GP is further metabo. lized by known pathways to form diacyl alkyl glycerol or complex phospholipids There are reports that plasmalogens may be biosynthesized from glycerol ethers (15), although in the present system no formation of plasmalogen was found. Addition of NAD stimulated the formation of alkali-stable lipid but the nature of the product was unchanged.

The present system is similar in many respects to the system found in preputlal gland tumors (2), especially in the requirements of cofactors. However, the specificity of acceptor is different. It will be of interest to elucidate the role of ATP and CoA. Further aspects of this novel biosynthesis of alkyl ether bond are under investigation in this laboratory.

Acknowledgment. This work is supported in part by grant NB 3101 from U.S. Public Health Service.

\section{REFERENCES}

1. Snyder, F., Progr. in chemistry of fats and lipids. 10, 287 (1969).

2. Snyder, F., R. L. Wykle and B. Malone, Biochem. Biophys. Res. Comm. 34, 315 (1969).

3. Snyder, F., R. L. Wykle and B. Malone, Fed. Proc. 28, 595 (1969).

4. Hajra, A. K., J. Biol. Chem. 243, 3458 (1968).

5. Szewczyk, A., E. Wolny, M. Wolny and T. Baranowski, Acta Biochim. Polon. 8, 201 (1961).

6. Hajra, A. K. and B. W. Agranoff, J. Biol. Chem. 243, 1609 (1968).

7. Hajra, A. K., Biochem. Biophys. Res. Comm. 33, 929 (1968).

8. Hajra, A. K. and B. W. Agranuff, J. Biol. Chem. 243, 1617 (1968).

9. Thompson, G. A., Jr. and P. Lee, Biochim. Biophys. Acta 98, 151 (1965).

10. Wood, R. and F. Snyder, Lipids 3 , 129 (1968).

11. Van Deenen, L. L. M. and G. H. DcHaas, Adv. Lipid Res. 2, 167 (1964).

12. Hajra, A. K. and B. W. Agranoff, J. Biol. Chem. 243, 3542 (1968).

13. Boxer, G. E. and C. E. Shonk, Biochim. Biophys. Acta 37, 194 (1960).

14. Desper, $P$. and 0 . Meyerhof, Arch. Biochem. 27, 223 (1950).

15. Goldfine, H., Ann. Rev. Biochem. 37, 303 (1968). 